\title{
A prospective study of causes and outcome of high risk pregnancies inreferred patients in a tertiary health care centre of southern Rajasthan
}

\author{
Kulshreshtha S. ${ }^{1}$, Babel M. ${ }^{2}$ \\ ${ }^{1}$ Dr. Shabdika Kulshreshtha, ${ }^{2}$ Dr. Meetu Babel; both authors are Assistant Professor, Department of Obstetrics \& \\ Gynaecology, Ananta Institute of Medical Sciences, Rajsamand, Rajasthan, India. \\ Corresponding Author: Dr. Meetu Babel, Assistant Professor, Department of Obstetrics \& Gynaecology, Ananta \\ Institute of Medical Sciences, Rajsamand, Rajasthan, India. Corresponding Address: 21, Lake City Hospital, Fatehpura, \\ Bedla Road, Udaipur. E-mail: dr.shikha9983@gmail.com
}

\begin{abstract}
Objective: The present study was conducted in a tertiary care health centre of southern Rajasthan to assess the prevalence of referred high risk pregnancy in the region and its outcome. Material \& Methods: 200 high risk pregnancies referred to our tertiary healthcare centre during the study period, which were not registered in our antenatal record; with gestation of $\geq 28$ weeks were included in the study. Obstetric outcomes were assessed in terms of maternal mortality and mode of delivery while neonatal outcomes were assessed in terms of incidences of intrauterine deaths, still births and live births. Results: Age of the patients' ranges from 18 to 45 years with the mean age of 24.7 years. $73.5 \%$ of the cases in present study were belonged to rural society while $26.5 \%$ cases belonged to urban society. The most common cause for referral of the patients in present study was history of previous LSCS (31\%) followed by anaemia (16\%), hypertensive disorder of the pregnancy (9\%) and bad obstetric history (9\%).44.5\% of the study participants had normal delivery while $54 \%$ had caesarean sections and the rest $1.5 \%$ had instrumental delivery (vacuum or forceps delivery). 200 study participants gave birth to 203 neonates (included 3 twin births). 97\% were the live birth while 3\% had intrauterine death and the rest $1.5 \%$ were stillborn. Conclusion: Early detection of high risk pregnancies at primary health care level with proper antenatal services and referral system is advisable to improve fetomaternal outcome.
\end{abstract}

Keywords: High risk pregnancy, Neonates, Maternal, Intrauterine death

\section{Introduction}

It is rightly said that giving birth itself is rebirth of a mother.Pregnancy is a physiologically dynamic state.A lot of changes occur in pregnancy whether it is morphological, hemodynamic or at cellular and metabolic levels. This brings a substantial risk to both mother and fetus in almost all pregnancies. High risk pregnancy (HRP) is defined as one where pregnancy is complicated by one or more factors that adversely affect the maternal and/ or perinatal outcome.About 20-30\% pregnancies belong to this category [1].

High risk patients require sophisticated maternal and fetal surveillance andin many occasions difficult management decisions in order to optimize their outcome [2].

Manuscript received: $6^{\text {th }}$ July 2019

Reviewed: $16^{\text {th }}$ July 2019

Author Corrected: $21^{\text {st }}$ July 2019

Accepted for Publication: $26^{\text {th }}$ July 2019
As per world health organization(WHO), approximately 830 women die from preventable causes related to obstetrics out of which $99 \%$ of all maternal deaths occur in developing countries. Maternal mortality is higher in women living in economically backward, rural areas [3].

The majority (75\%) of maternal deaths are due to:

- Antepartum and postpartum haemorrhage

- Sepsis

- Hypertensive disorders of pregnancy

- Intrapartum complications

- Septic abortion.

Remaining $25 \%$ are due to medical complications like heart diseases, human immunodeficiency virus (HIV)/full blown acquired immunodeficiency syndrome (AIDS), gestational diabetes mellitus (GDM), jaundice, anaemia and malaria during pregnancy [4]. 
Therefore it is our endeavour to evaluate the causes of HRPs and thereby decrease the maternal mortality rate (MMR) by early interventions during pregnancy. Quite unexpectedly, there is a lot of focus on reducing MMR but few recognize the need of identifying the high risk pregnancies in correlation with their fetomaternal outcome. In the region of South Rajasthan (Mewar) the present study was conducted at tertiary health centre in the rural area of Rajsamand where a lot of HRPs are referred from adjoining areas.It is evident that providing quality obstetric care to HRP patients can substantially reduce maternal mortality rate (MMR) as well as neonatal mortality rate(NMR).

\section{Material \& Methods}

The present study is a prospective study carried out in the Department of Obstetrics \& Gynaecology, Ananta Institute of Medical Sciences \& Research Centre, Rajsamand for the duration of six months from January 2016 to July 2016.

Setting: Tertiary care health centre

Type of study: Prospective longitudinal study

Duration: 6 months duration from January 2016 to July 2016

Participants: During the study period, first 200 patients of high risk pregnancy with gestation $\geq 28$ weeks referred to the institute were included in the study. These patients were referred from the adjoining areas of Rajsamand including rural and urban. All these patients were admitted, interviewed and thoroughly examined. Patients were evaluated in terms of their demographic profile, causes of referral, mode of delivery and their fetal outcome. Well-informed, written consent was taken from all the patients.It was ensured that their personal details including obstetric history would remain confidential.

Inclusion criteria:High risk pregnancies referred to our tertiary healthcare centre during the study period, which were not registered in our antenatal record; with gestation of $\geq 28$ weeks were included in the study.

All 200 referred HRPs were categorized into 15 categories viz.

- Teenage pregnancy (Age of mother $<20 \mathrm{yrs}$ )
- Anaemia $(\mathrm{Hb}<11$ gram\%)

- Hypertensive disorders of pregnancy (Gestational hypertension,preeclampsia,eclampsia)

- Bad obstetric history (history of previous obstetric disaster which has possibilities to affect the present pregnancy)

- Gestational diabetes mellitus( 2 hour blood value of 75 gram oral glucose tolerance test $>155 \mathrm{mg} / \mathrm{dl}$ )

- Grand multipara (pregnant female with previous 4 or more viable births)

- Multifetal pregnancy (Twins,triplets and so on)

- Congenital malformations (including neural tube defects,cardiovascular(CVS) anomalies, Gastrointestinal malformations, chromosomal abnormalities)

- Recurrent pregnancy loss(Sequence of three or more consecutive spontaneous abortion $<20$ weeks)

- Previous Lower segment caesarean section

- Fibroid uterus (Leiomyoma associated with pregnancy)

- Antepartum Haemorrhage (including Placenta praevia and Abruptio placentae)

- Heart diseases in pregnancy (Rheumatic heart disease,congenital heart disease, cardiomyopathies)

- Malpresentation (Presentations other than vertex viz. breech,face,brow, transverse, unstable or compound)

- Pregnancies with negative Rh factor blood group.

Health outcomes of all the pregnancies recorded were:

1. Obstetric outcome (maternal mortality and morbidity, mode of delivery i.e. normal, operative or instrumental)

2. Neonatal outcome (incidence of intrauterine death, still birth, live birth)

\section{Exclusion criteria}

- All pre-booked cases that were already registered in antenatal record of the institute.

- Unbooked cases with uneventful pregnancy and normal delivery.

- Cases who refused to give consent.

Ethical consideration: permission to conduct study was taken from institutional ethical committee. Well informed written consent was taken from all the study participants.

\section{Results}

200 pregnant females who matched the inclusion criteria during the period of 6 months from January 2016 to July 2016 were included in present study. In present study, age of the patients ranges from 18 to 45 years with the mean age of 24.7 years. $73.5 \%$ of the cases in present study were belonged to rural society while $26.5 \%$ cases were belonged to urban society. Table 1 describes the socio-demographic pattern of the patients included in present study. 
Table-1: Socio-demographic profile of the study participants

\begin{tabular}{|c|c|c|}
\hline Age (in years) & No. of pts & Percentage (\%) \\
\hline$<20$ & 4 & 51 \\
\hline $20-25$ & 102 & 43 \\
\hline $25-30$ & 86 & $\mathbf{1 0 0}$ \\
\hline$>30$ & 8 & 73.5 \\
\hline Total & $\mathbf{2 0 0}$ & 26.5 \\
\hline Society distribution of the patients & & $\mathbf{1 0 0}$ \\
\hline Rural & 147 & \\
\hline Urban & 53 & $\mathbf{2 0 0}$ \\
\hline
\end{tabular}

The most common cause for referral of the patients in present study was history of previous LSCS (31\%) followed by anaemia (16\%), hypertensive disorder of the pregnancy (9\%) and bad obstetric history (9\%). (Table 2)

Table-2: Indications for referral of the patients

\begin{tabular}{|c|c|c|c|}
\hline S.No. & Indications of high risk pregnancy & No. of pts. & Percentage $(\%)$ \\
\hline 1 & Teenage pregnancy & 4 & 2 \\
\hline 2 & Anaemia & 32 & 16 \\
\hline 3 & Hypertensive disorders of pregnancy & 18 & 9 \\
\hline 4 & Bad obstetric history & 18 & 9 \\
\hline 5 & Gestational diabetes mellitus & 6 & 3 \\
\hline 6 & Grand multipara & 8 & 4 \\
\hline 7 & Multifetal pregnancy & 3 & 1.5 \\
\hline 8 & Congenital malformation & 1 & 0.5 \\
\hline 9 & Recurrent pregnancy loss & 11 & 5.5 \\
\hline 10 & Previous LSCS (one or more) & 62 & 31 \\
\hline 11 & Fibroid uterus & 3 & 1.5 \\
\hline 12 & A.P.H (antepartum haemorrhage) & 7 & 3.5 \\
\hline 13 & Heart disease & 3 & 1.5 \\
\hline 14 & Malpresentation & 13 & 6.5 \\
\hline \multirow[t]{2}{*}{15} & $\mathrm{Rh}$-vepregnancy & 11 & 5.5 \\
\hline & Total & 200 & 100 \\
\hline
\end{tabular}

$44.5 \%$ of the study participants had normal delivery while 54\% had caesarean sections and the rest $1.5 \%$ had instrumental delivery (vacuum or forceps delivery) (Table 3)Fortunately, there was no maternal mortality in present study participants.

Table-3: Obstetric outcome in terms of mode of delivery

\begin{tabular}{|c|c|c|}
\hline Mode of delivery & No. of pts & Percentage (\%) \\
\hline Normal & 89 & 44.5 \\
\hline Operative & 108 & 54 \\
\hline Instrumental & 3 & 1.5 \\
\hline Total & $\mathbf{2 0 0}$ & $\mathbf{1 0 0}$ \\
\hline
\end{tabular}

Table-4: Fetal outcome in the present study

\begin{tabular}{|c|c|c|}
\hline Fetal outcome & Number of neonates & Percentage \\
\hline Intra uterine death & 6 & 3 \\
\hline Still birth & 3 & 1.5 \\
\hline Live birth & 194 & 97 \\
\hline Total & $\mathbf{2 0 3}^{*}$ & $\mathbf{1 0 1 . 5}$ \\
\hline
\end{tabular}

*3 Twin Births (2 live births and 1 intrauterine death) 


\section{Original Research Article}

200 study participants gave birth to 203 neonates (included 3 twin births). 97\% were the live birth while $3 \%$ had intrauterine death and the rest $1.5 \%$ were stillbirth. (Table 4 )

\section{Discussion}

In present study,majority of the patients $(94 \%)$ were in the age group 20-30 years followed by $4 \%$ in the age group $>30$ years and $2 \%$ in the age group $<20$ years. Many studies done in the past had similar findings [5, 6, 7]. In a study by Pradeep Kumar et al in 2015, majority of the patients $(76 \%)$ belonged to the age group of 20 30 years [5]. As per another study by Jaideep et al in 2017, 81\% patients were between 20-29 years of age [6]. Majella et al performed a similar study in 2019 and reported $86.4 \%$ patients were in the age group of $20-30$ years [7].

As far as residence is concerned, 73.5\% patients of present study were from rural area and rest $26.5 \%$ were from urban area. The reason behind this finding might be because of the location of our institute which itself is located in rural area and most of its catchment areas are nearby villages.In another study conducted by Jnaneswari et al in 2016, $60 \%$ patients were from urban society while $20 \%$ patients were rural and rest $20 \%$ were semi urban [8].

In a similar study conducted by Aysha Beegom et al in 1998, 90.5\% patients were from rural background and remaining $9.5 \%$ were from urban area [9].

In the present study,54\% patients delivered by LSCS followed by $44.5 \%$ by normal vaginal delivery and rest $1.5 \%$ by instrumentation delivery.In a study conducted by Jadhao et al in $2017,68.06 \%$ of high riskpregnancies delivered by LSCS while remaining delivered by vaginal route [10]. Another study conducted by Majella et al in 2019 revealed that $67 \%$ patients delivered by LSCS, $30.9 \%$ patients by spontaneous vaginal delivery and remaining $2.1 \%$ patients by assisted vaginal delivery [7]. In the study by Jnaneswari et al in 2016, $71.6 \%$ patients underwent normal delivery and rest $28.3 \%$ had LSCS done [8].

In the present study, the reasons of referral of high risk pregnancy are innumerated in table 2. Previous LSCS (31\%) was reported to be the most common cause of referral followed by anaemia (16\%). Bad obstetric history $(\mathrm{BOH})$ and pregnancy induced hypertension (PIH) were equally contributing to high risk pregnancy ( $9 \%$ each). Other less common causes were grand multipara, gestational diabetes, pregnancy with congenital malformations, multiple pregnancies, fibroid uterus with pregnancy, pregnancy with heart disease etc.
As per a similar study performed by Aysha B et al in 1998 in Kerala, elevencauses were categorized for referrals among which PIH (18.8\%), fetal complications (18.6\%) and premature rupture of membranes (PROM) $(12.9 \%)$ were the three leading causes. Infections like sexually transmitted diseases (STDs/ hepatitis) wereamong the rarest causes $(2.88 \%)$. An interesting feature to note was referrals for no reasons $(7.13 \%)$ being a category simply because many hospitals were not equipped for conducting deliveries [9].

Jadhao et al performed a similar study in 2017 in Nagpur and reported previous LSCS (14.49\%), malpresentation (7.94\%) and teenage pregnancy $(6.54 \%)$ were the commonest risk factors for HRPs [10].

Bharti et al, in 2013, conducted a study in rural region of Haryana and observed that recurrent abortions (27.4\%), short stature (24.7\%) and PIH were the leading causes of high risk pregnancy. Among rarer ones were elderly primi $(2.4 \%)$, congenital malformations $(3.8 \%)$ and previous LSCS (8.2\%) [11].

In a study conducted by $\mathrm{M}$ Pradeep Kumar et al in 2015, short stature (40.5\%), recurrent abortions (29.7\%) and previous LSCS (13.5\%) were the leading causes of high risk pregnancy. [5]. Similarily, Jnaneswari et al conducted a study in Puducherry in 2016 and reported that anaemia (36.6\%), PIH (35.2\%), GDM (14.08\%) were the most common causes of HRP. (8) Another study from Iran by F Farajnezhad highlighted abnormal BMI (23.52\%) and previous LSCS (17.1\%) as commonest risk factors for HRP. Renal diseases $(0.7 \%)$ and GDM (0.8\%) hold less risk for HRP [12].

The evaluation of fetal outcome in present study was done by assessing the condition of newborn at birth and was classified into intrauterine deaths, still births and live births. A reasonably fair outcome of 194 (97\%) live births was recorded in present study on account of amicable management,prompt decision making, laudable neonatal intensive care unit(NICU) facilities and timely referral from peripheries to our hospital. 3\% were intrauterine deaths and $1.5 \%$ were stillborn in present study. In earlier studies, the incidence of neonatal deaths were high, might be because of poor health services in the past. With the advancement of health services and improved referral system, the incidence has declined in recent studies. 
In a study conducted by Aysha B et al in 1998 from Kerala, the occurrence of preterm babies $(10.9 \%)$ and low birth weight (LBW) babies (15.9\%) was observed to be very high. There were 103 neonatal deaths out of which 89 were perinatal deaths. Of these, 66 were still births, 23 were early neonatal deathsand 14 were preterm LBW(weight $<1000 \mathrm{gm}$ ) [9].

A similar study conducted by Jnaneswari et al in 2016 in Puducherry showed $98.3 \%$ live births against $1.7 \%$ still born [8]. Jadhao et al, in their study in 2017 observed that the live births were as high as $98.61 \%$ compared to still births (1.39\%) [10]. A latest study from Puducherry by Majella et al showed 94.9\% live births, $3.4 \%$ abortions and $1.7 \%$ still birth [7].

Limitations of the present study- The study included a small sample size of a particular region. The most of the patients included in present study were from rural back ground. The result obtained may not be generalizable to some other region or to the urban population. Further, a large sample size can provide us the better information regarding high risk pregnancy.

\section{Conclusion}

The present study concluded that majority of high risk referred patients to our institute were from rural background. Most of these patients were in the reproductive age group of 20-30 years. Most common cause of referral of HRP was previous LSCS followed by anaemia and bad obstetric history. Fortunately, most of the fetomaternal outcomes in present study were favorable, still unfavorable outcomes like maternal death, intrauterine death, stillborn and low birth weight babies are not uncommon in rural areas because of lack of health education and poor referral services. Hence, early detection of high risk pregnancies at primary health care level with proper antenatal services and referral system is advisable to improve fetomaternal outcome. Programes like 'safe motherhood day' initiated by government of India are welcomed in which private practitioners are invited to community health centers for HRP screening on $9^{\text {th }}$ of every month.

\section{What this study adds to existing knowledge?}

The present study was first of its kind in the area of southern Rajasthan. The study suggested that most common causes of referral of high risk pregnancy in southern part of Rajasthan are previous LSCS followed by anaemia and bad obstetric history. The results of this study will help the practitioners to identify common causes of high risk pregnancies in that area so as to take guided steps to improve antenatal services.

\section{Author'scontribution}

Dr. Shabdika Kulshreshtha: Study concept and design, revision and proof.

Dr. Meetu Babel: Data analysis, statistics, drafting.

Funding: Nil, Conflict of interest: Nil

Permission from IRB: Yes

\section{References}

1. Dutta D C, Text book of Obstetrics. New Central book Agency (P) Ltd, Calcutta, India. 2015

2. Arias F, Bhide AG, Arulkumaran S, Damania K, Daftary SN, editors. Practical Guide to High Risk Pregnancy and Delivery-E-Book: A South Asian Perspective. Elsevier health sciences; 2012.

3. Alkema L, Chou D, Hogan D, Zhang S, Moller $\mathrm{AB}$, Gemmill A, et al. Global, regional, and national levels and trends in maternal mortality between 1990 and 2015, with scenario-based projections to 2030: a systematic analysis by the UN Maternal Mortality Estimation Inter-Agency Group. Lancet. 2016;387 (10017): 462-74. doi: 10.1016/S0140-6736(15)00838-7. Epub 2015.

4. Say L, Chou D, Gemmill A, Tunçalp Ö, Moller AB, Daniels J, et al. Global causes of maternal death: a WHO systematic analysis. Lancet Glob Health. 2014;2 (6):e323-33. doi: 10.1016/S2214-109X(14) 70227-X. Epub 2014.

5. Pradeep MK, Gnanadeep NV, Umesh RD, Pushpa SP. Prevalence of high risk pregnancy in rural Dharwad. IOSR J Dent MedSci. 2015; 14 (10):29-32. doi: 10.9790/ 0853-141062932

6. Jaideep KC, Prashant D, Girija A. Prevalence of high risk among pregnant women attending antenatal clinic in rural field practice area of Jawaharlal Nehru Medical College, Belgavi, Karnataka, India. International Journal of Community Medicine And Public Health. 2017;4(4):1257-9.doi: http://dx.doi.org/10.18203/23946040.ijcmph20171359

7. Beegom Aysha A. A Prospective descriptive study of the clinical outcomes of high risk pregnancies at a public sector tertiary care centre, Kerala. Dissertation work. dspace.sctimst.ac.in/jspui/bitstream/123456789/ 2204/1/591.pdf 
8. Jnaneswari K, Manjubala D. Perinatal outcome in high risk pregnancies. Int Res J Med Sci.2016;4(4):1-4.

9. Majella MG, Sarveswaran G, Krishnamoorthy Y, Sivaranjini K, Arikrishnan K, Kumar SG. A longitudinal study on high risk pregnancy and its outcome among antenatal women attending rural primary health centre in Puducherry, South India. J Educ Health Promot. 2019;8:12. doi: 10.4103/jehp.jeh p_144_18. eCollection 2019.

10. Jadhao AR, Gawade MD, Ughade SN. Outcome of pregnancy among high risk pregnancies in rural area of
Nagpur, Central India. Int J Commun Med Public Health. 2017;4 (3): 628-33. doi: http://dx.doi.org/ 10.18203/2394-6040. ijcmph20170443

11. Mehta B, Vijay K, Amamdeep K , Sumit C, Manisha M. Prevalence and correlates of high risk pregnancy in rural Haryana: A community based study. Int J Basic Appl Med Sci.2013;3(2):212-7

12. Farajnezhad F, Shaahmadi F, Fashi Z, Daaylar L. Prevalence of high risk pregnancy and some relevant factors in referred women to health centers. J Sci Achieve. 2017;2(12):4-7.

\section{How to cite this article?}

Kulshreshtha S., Babel M. A prospective study of causes and outcome of high risk pregnancies inreferred patients in a tertiary health care centre of southern Rajasthan. Obs Rev: J obstet Gynecol 2019;5(3):141146.doi:10.17511/joog.2019.i03.03. 